\section{Effect of Fertilizer Application Level on Pectin Composition of Hakuho Peach (Prunus persica Batsch) During Maturation}

\author{
H.J. Jia ${ }^{1}$ \\ Department of Horticulture, Zhejiang University, Hangzhou 310029, China
}

K. Mizuguchi, K. Hirano, and G. Okamoto

Department of Applied Plant Science, Okayama University, Okayama 700-0583, Japan

Additional index words. peach, flesh pectin composition, fertilizer application

\begin{abstract}
Effects of fertilizer application levels on fruit texture and flesh pectin compositions of a melting peach were investigated. Hakuho trees (Prunus persica Batsch) were supplied with normal $(M)$, high $(H ; M \times 2)$, and superhigh $(\mathrm{SH} ; \mathrm{M} \times 4)$ levels of complete liquid fertilizer twice a week. Flesh firmness of the $\mathbf{H}$ and $\mathrm{SH}$ treatment fruit was lower than that of $M$ treatment fruit at the hard-mature and firm-mature stages, although no difference was detected at the full ripe stage. Sensory scores for flesh texture at the full ripe stage were highest in the $\mathrm{N}$ treatment fruit and lowest in the SH treatment fruit. The content of water-soluble polyuronides (WSP) in flesh was highest in SH fruit and lowest in $M$ fruit at the hard-mature stage, although the difference became smaller at the full ripe stage. Molecular mass analysis using a gel filtration column revealed that water-soluble polysaccharides in alcohol-insoluble solids (AIS) of the $\mathrm{H}$ and $\mathrm{SH}$ fruits had a peak of high molecular mass, $\approx 200 \mathrm{kDa}$, at the hard-mature stage, and the molecular mass decreased gradually to $\approx 23 \mathrm{kDa}$ at the full ripe stage. In the $\mathrm{M}$ fruit, however, the molecular mass was rather constant during the ripening period, $112 \mathrm{kDa}$ even at the full ripe stage. The analysis of acidic fractions (pectin) in the polysaccharides using an ion exchange column, as well as juice gellation test by adding $\mathrm{Ca}$ and Tris buffer, also indicated that high levels of fertilizer application impairs an early degradation of flesh polyuronides resulting in the accumulation of low-molecular-weight WSP. This may ultimately cause the inferior flesh texture of overfertilized peach fruit.
\end{abstract}

The melting peach (Prunus persica Batsch), a climacteric fruit, has a smooth and juicy flesh, an attractive aroma, and a desirable taste at its fully ripe stage that continues to enjoy a large share of the market in Japan. However, it has a particularly short postharvest life because it softens to a "melting" texture within a few days at room temperature. Thus, the softening of peaches is one of the critical factors that limits storage duration and shelf life.

Fruit texture is influenced by environmental, cultural, physiological, and genetic factors (Sams, 1999). Cultivation practices such as fertilizer application and growth regulator use, irrigation, pruning, time of harvest, and cultivar selection have a major impact on fruit texture. In our previous work, Hakuho peaches grown under high nitrogen fertilization conditions had deterioration of flesh texture and flavor compared with those har-

\footnotetext{
Received for publication 22 May 2006. Accepted for publication 13 Aug. 2006.

We thank Dr. Yoshinobu Kimura for his skillful analyses and useful comments on the manuscript.

${ }^{1}$ To whom reprint requests should be addressed; e-mail jiahuijuan@zju.edu.cn.
}

vested from moderately or lightly fertilized trees as well as a delayed harvest date (Jia et al., 1999, 2000; Okamoto et al., 2001). This undesirable decrease in flesh firmness resulting from excessive fertilization has been well documented in other fruit crops (Blanpied et al., 1978; Reeve, 1970).

The softening and textural changes that occur during fruit ripening are characteristic of particular species and are the result of differences in cell wall thickness and composition, cell size, shape, packing, contents, and turgor (Harker et al., 1997). Pressey and Avants (1978) have demonstrated that peach softening is accompanied by the conversion of water-insoluble pectin into water-soluble pectin (WSP), and the molecular masses of pectic polymers extracted from the fruit mesocarp cell wall shift from larger to smaller polymers during fruit softening were reported by Fishman et al. (1993), Maness et al. (1993), and Hegde and Maness (1996, 1998). Chen and Mellenthin (1981) reported that pears of good quality develop a buttery and juicy texture, which is associated with the reduction in extractable juice. Such a desirable texture may be a result of an increase in the solubility of polyuronides in the pulp; fruit did not ripen normally never developed the buttery and juicy texture of ripe fruit. These results suggest that WSP content is closely related to the texture of ripening fruits. Although changes in other polysaccharides may be involved, the solubilization of pectin has received the highest attention because of the preponderance of this polysaccharide in the middle lamella of flesh cells.

The mechanisms and processes behind the chemical and structural changes in flesh cell walls during ripening have been investigated by numerous researchers. However, the effect of field practices such as fertilizer application level on the fruit pectin composition has been poorly documented. The objective of our work is to further elucidate the softening processes in peaches by investigating the changes in the physicochemical properties of pectin substances at various fruitripening stages.

\section{Materials and Methods}

Plant material and treatments. Twentyfour 6-year-old trees of Hakuho peach (Prunus persica Batsch) growing in the Experimental Orchard of Okayama University, Japan, were used for this study in 2003. They were trained to a central leader system and planted in buried pots $(120 \mathrm{~L})$ made of rootproof but water-permeable cloth. Three levels of complete liquid fertilizers (OHTUSKA EKIHI \#1 and \#2) containing 60, 120, and $240 \mathrm{ppm} \mathrm{N}$ (medium, M; high, H; super high, $\mathrm{SH}$, respectively) were applied $15 \mathrm{~L}$ per tree (seven trees per fertilizer treatment) and twice a week from bud burst (14 Mar.). The complete liquid fertilizers inclusive all essential elements as shown in our previous paper (Jia et al., 1999). The fertilizer application levels in each treatment were reduced to half at the end of the pit hardening stage in late May. Fruit thinning were practiced to adjust the leaf-fruit ratio 30 to 40 leaves/fruit during late May as often practiced in Okayama Prefecture and covered with orange paper bags to avoid insect and fungal attack.

Fruit sampling, flesh firmness, and sensory evaluation. To limit the effects of the maturation stage on results, 60 fruits were harvested at different dates depending on the skin color from each treatment. Fruits were sampled at three stages: immature stage (still greenish, $103 \mathrm{~d}$ after full bloom), firm-mature stage (just changed from green to white, $108 \mathrm{~d}$ after full bloom), and fully ripe (harvested at the firm-mature stage and stored for $3 \mathrm{~d}$ at $25{ }^{\circ} \mathrm{C}$ ). Thirty flesh firmness of each sample was measured according to the method of Okamoto et al. (2001). Two square pillars $(1.5 \times 1.5 \mathrm{~mm})$ with the entire thickness of the mesocarp were excised from both cheeks of each fruit and pressed with a penetrometer (TOYO BOLDWIN, STM-T) having a plunger $(\$ 8 \mathrm{~mm})$ at the rate of $30 \mathrm{~mm} \cdot \mathrm{min}^{-1}$. The internal stress was recorded when the height of the pillar was decreased by $5 \%$. 
After determining flesh firmness, each fruit was peeled, and two wedge-shaped sectors were cut from the fruit, diced into $1.5 \times 1.5 \mathrm{~cm}$, and placed in coded containers for tasting. The taste evaluations were made by a 15 -member trained sensory panel who rated on fine texture as described previously by Jia et al. (2000). Final taste ratings were: $1=$ unacceptable, 2 = poor, $3=$ fine, or $4=$ excellent. The rank test method was used for evaluating. Other cubes were homogenized and centrifuged at $10,000 \times g$ for $15 \mathrm{~min}$ and then filtered. The supernatants were weighed to calculate the percentage of extracted juice from flesh. Total soluble solids, titratable acidity, and nitrogen were measured using previously reported method (Jia et al., 1999).

Cell wall isolation and pectin polysaccharide extraction. Cell wall polyuronides were prepared from alcohol-insoluble residues of flesh and portioned into three fractions based on solubility in different solvents according to the procedure of Murayama et al. (2002) with some modification. Twenty-gram homogenized flesh samples were extracted three times with $80 \% \mathrm{EtOH}$ at $70{ }^{\circ} \mathrm{C}$ and centrifuged to obtain alcohol insoluble solids (AIS). They were then lyophilized and pulverized. The residue was suspended in $100 \mathrm{~mL}$ of distilled water, stirred overnight at $25^{\circ} \mathrm{C}$, and filtered. The filtrates were combined and designated as the WSP. The residue was resuspended in 100 $\mathrm{mL}$ of $50 \mathrm{~mm}$ ethylenediaminetetraacetic acid (EDTA) in $50 \mathrm{~mm}$ sodium phosphate $(\mathrm{pH} 4.5)$ at $25{ }^{\circ} \mathrm{C}$ for $30 \mathrm{~min}$. The filtrates were combined and designated as the chelator-soluble polyuronides (CSP). The residue was further extracted twice with $50 \mathrm{~mL}$ of $50 \mathrm{~mm} \mathrm{Na}_{2} \mathrm{CO}_{3}$ containing $20 \mathrm{~mm} \mathrm{NaBH}_{4}$ at $25{ }^{\circ} \mathrm{C}$. The filtrates were combined, neutralized with acetic acid, and designated as the alkali-soluble polyuronides (ASP). The uronic acid content in each fraction was determined by the carbazole $-\mathrm{H}_{2} \mathrm{SO}_{4}$ method. The residue after the extraction of pectic polysaccharide, hemicellulosic polysaccharides, was further extracted using $1 \mathrm{~m} \mathrm{KOH}$ and $4 \mathrm{~m} \mathrm{KOH}$. The final residue was collected as cellulose (Murayama et al., 2002). Both hemicellulose and cellulose were hydrolyzed with $\mathrm{HCl}(0.5 \mathrm{~N})$ at $100{ }^{\circ} \mathrm{C}$ for $2.5 \mathrm{~h}$ to reducing sugars that were determined by the phenol- $\mathrm{H}_{2} \mathrm{SO}_{4}$ method.

Size exclusion chromatography and ion exchange chromatography. Water-soluble polysaccharides extracted from AIS were chromatographed on a size-exclusion column (TSK-GEL G5000PW + G3000PW, 7.5 mm ID $\times 60 \mathrm{~cm} \times 2, \mathrm{TOSOH})$ and eluted with $0.025 \mathrm{M}$ phosphate buffer ( $\mathrm{pH} 7.5$ ) plus $0.2 \mathrm{M}$ $\mathrm{NaCl}$ at $25{ }^{\circ} \mathrm{C}$. The molecular weight distribution of the cell wall polyuronides was estimated by gel filtration with high-performance liquid chromatography (HPLC) equipped with an RI detector (RI-1530; JASCO) using pullulan fragments (Shodex standard P-82; Showa Denko K.K. Japan) as molecular markers. Samples $(200 \mu \mathrm{L})$ were injected and eluted at a flow rate of 0.5 $\mathrm{mL} \cdot \mathrm{min}^{-1}$. Peaks were detected using a re- fractive index detected (model R401; Waters Associates, Inc. Amherst, Mass.); $1.5 \mathrm{~mL}$ of fractions were collected at 1-min intervals and pooled based on the elution time of peaks of interest. Neutral and uronic acid polysaccharides of the cell wall in the water-soluble polysaccharides were fractionated by ion exchange chromatography with HPLC equipped with a quaternary amine column (POROS HQ/M, $4.6 \mathrm{mmD} \cdot 100 \mathrm{~mm}^{-1} \cdot \mathrm{L}$; PerSeptive Biosystems) equilibrated with $50 \mathrm{~mm}$ Tris- $\mathrm{HCl}$ buffer ( $\mathrm{pH} 8.5$ ) as described (Hegde and Maness, 1998). Neutral polysaccharides were first eluted out through the column. The polyuronides that were retained in the column were them eluted with a linear gradient of 0 to $0.5 \mathrm{M} \mathrm{NaCl}$ solution. Column fractions were quantified for contents of uronic acid content was using the assay of Blumenkrantz and Asboe-Hansen, (1973) with galacturonic acid as the standard.

Juice gellation measurement. To elucidate the physicochemical properties of juice pectin in each treatment fruit juice, gel formation after $\mathrm{Ca}^{2+}$ addition under different $\mathrm{pH}$ conditions was determined. $\mathrm{CaCl}_{2}$ was added to the three juice solutions come from 20 fruits, and the $\mathrm{pH}$ was adjusted to 7.8 with Tris buffer. Juice mixtures without Tris buffer and with only $\mathrm{H}_{2} \mathrm{O}$ were also evaluated. The viscosity of each mixture was determined with an Ostwald viscosimeter $(1.0 \mathrm{~mm}$ ID and $20 \mathrm{~cm}$ total length) at $25^{\circ} \mathrm{C}$. The flow times were recorded for each 5-mL test solution.

\section{Results}

Effect of fertilizer application level on fruit weight, flesh $N$, and juice quality. The average fruit weight was increased as the fertilizer application level was increased; a significant difference was observed between $\mathrm{M}$ and $\mathrm{SH}$ treatment fruits (Table 1). A similar trend was observed in the case of flesh nitrogen content. The TSS content of juice was the lowest in the $\mathrm{SH}$ treatment fruits and the TA was the highest in the M treatment fruits. Sensory evaluation of flesh texture showed significant differences among the three treatments fruits at the fully ripe stage. The tasters frequently commented that the texture of the $\mathrm{M}$ treatment fruits was buttery and juicy, whereas that of the $\mathrm{H}$ and SH treatment fruits was rough (Table 1).

Effect of fertilizer application level on flesh firmness. Flesh firmness differed signif-

Table 1. Effect of fertilizer application level on fruit weight, flesh $\mathrm{N}$, and juice composition of Hakuho peaches.

\begin{tabular}{|c|c|c|c|c|c|}
\hline \multirow[b]{2}{*}{ Treatment $^{\mathrm{z}}$} & \multirow[b]{2}{*}{ Fruit wt (g per fruit) } & \multicolumn{2}{|c|}{ Flesh } & \multicolumn{2}{|c|}{ Juice } \\
\hline & & $\mathrm{N}\left(\mathrm{mg} \cdot \mathrm{g}^{-1} \mathrm{DW}\right)$ & Sensory score ${ }^{x}$ & $\overline{\mathrm{TSS}}\left({ }^{\circ} \mathrm{Brix}\right)$ & $\mathrm{TA}\left(\mathrm{g} \cdot \mathrm{L}^{-1}\right)^{\mathrm{w}}$ \\
\hline$\overline{\mathrm{M}}$ & $232.4 \mathrm{~b}^{\mathrm{y}}$ & $10.10 \mathrm{bc}$ & $38 \mathrm{a}$ & $14.4 \mathrm{a}$ & $1.59 \mathrm{a}$ \\
\hline $\mathrm{H}$ & $249.8 \mathrm{ab}$ & $11.2 \mathrm{~b}$ & $28 \mathrm{~b}$ & $14.2 \mathrm{a}$ & $1.47 \mathrm{~b}$ \\
\hline $\mathrm{SH}$ & $259.1 \mathrm{a}$ & $13.8 \mathrm{a}$ & $24 \mathrm{c}$ & $13.5 \mathrm{~b}$ & $1.49 \mathrm{~b}$ \\
\hline
\end{tabular}

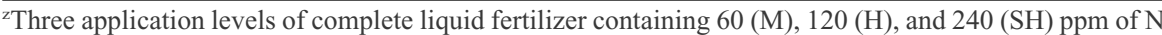
were supplied once a week. Fruits were harvested at the firm-mature stage and stored for $3 \mathrm{~d}$.

${ }^{y}$ Significant difference by Duncan's multiple range test $(P \leq 0.05)$ for values within each column.

${ }^{x}$ Sensory evaluation by 15 panelists and analyzed by the rank sum test $(P \leq 0.05)$. Higher values indicate fine texture.

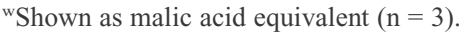

icantly among the three treatment fruits at the hard-mature stage (Fig. 1). At the firmmature stage, flesh firmness was the highest tion level was increased, the flesh firmness of the mature fruit was decreased; however, no significant difference was found among the hree treatment fruits at the fully ripe stage. the in the $M$ treatment fruits; in contrast there was almost no change in flesh firmness in the $\mathrm{SH}$ treatment fruits.

Effect of fertilizer application level on yield and composition of cell wall substances. The percentage expressed juice from the flesh was similar at the hard-mature and firmext the fully ripe stage (Table 2 ). On the other hand, no significant difference was found among the treatment fruits at each stage. The AIS content of flesh was treatment fruits contained much lower AIS than the other treatment fruits.

The WSP content was lower in the M treatment fruits than in the $\mathrm{H}$ or $\mathrm{SH}$ treatment fruits at the three harvest stages (Table 3 ). WSP content was the highest in the SH stages. The CSP content did not change substantially in the $\mathrm{M}$ and $\mathrm{H}$ treatment fruits but decreased in the $\mathrm{SH}$ treatment fruits with creasing maturity. The ASP content varied slightly among the three treatment fruits at the hard- and firm-mature stages. However, -marked decrease was found in the SH cellulose was detected in small quantities in all the treatment fruits, and no significant difference was observed among the three stages. Cellulose content was decreased gradually with increasing maturity, although no significant difference was found among the three treatments

Effect of fertilizer application level on molecular mass distribution of water-soluble traction extracted from alcoholinsoluble solids. As fruit maturity was increased, the amount of high-molecular-mass increased (Fig. 2). This was particularly evident in the $\mathrm{H}$ and $\mathrm{SH}$ treatment fruits at the firm-mature and fully ripe stages. At the hard-mature stage, an apparent increase in ches intermediate- 


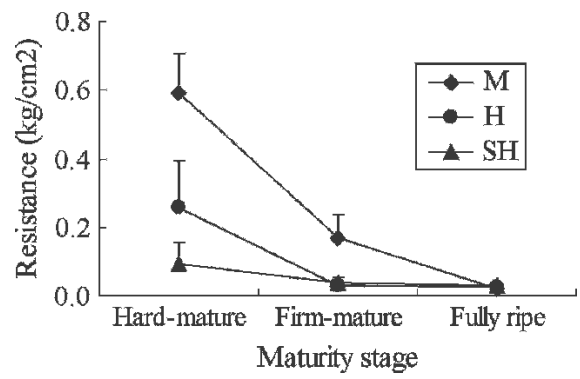

Fig. 1. Effect of fertilizer application level on flesh firmness of Hakuho peaches. Fruits were sampled at three stages: hard-mature stage (still greenish), firm-mature stage (white), and fully ripe stage (harvested at the firm-mature stage and stored for $3 \mathrm{~d}$ at room temperature).

the peak of WSP was observed as the fertilizer application level was increased. Moreover, a high proportion of intermediatemolecular-mass pectin that was fractionated between 212 and $47 \mathrm{kDa}$ was detected in the $\mathrm{H}$ and $\mathrm{SH}$ treatment fruits compared with that in the $\mathrm{M}$ treatment fruits. At the firm-mature stage, an apparent decrease in molecular mass of WSP was observed in the $\mathrm{H}$ and SH treatment fruits from a peak at $212 \mathrm{kDa}$ to that at $27 \mathrm{kDa}$. On the other hand, the peak around 212 to $112 \mathrm{kDa}$ was retained in the $\mathrm{M}$ treatment fruits. At the fully ripe stage, molecular mass of WPS decreased faster in the $\mathrm{H}$ and $\mathrm{SH}$ treatment fruits, indicated by a peak that corresponded to the $22.8 \mathrm{kDa}$ molecular marker. In the case of the $M$ treatment fruits, however, the molecular mass of WPS was retained at $112 \mathrm{kDa}$.

Effect of fertilizer application level on content of acidic pectic polysaccharides in water-soluble polyuronide fraction of alcohol-insoluble solids. The elution profiles of acidic pectic polysaccharides extracted from the WSP fraction of AIS are shown in Figure 3. At the hard-mature stage, the

Table 2. Effect of fertilizer application level on percentage of extracted juice and alcoholinsoluble solids (AIS) content of Hakuho peach flesh.

\begin{tabular}{ccc}
\hline Treatment & $\begin{array}{c}\text { Extractable } \\
\text { juice }(\%)\end{array}$ & $\begin{array}{c}\text { AIS } \\
\left(\mathrm{mg} \cdot \mathrm{g}^{-1} \mathrm{FW}\right)\end{array}$ \\
\hline Hard-mature & $73.09 \mathrm{~cd}^{\mathrm{y}}$ & $1.08 \mathrm{~d}$ \\
M & $72.93 \mathrm{~cd}$ & $2.36 \mathrm{c}$ \\
H & $71.69 \mathrm{~d}$ & $3.49 \mathrm{bc}$ \\
SH & & \\
Firm-mature & $73.41 \mathrm{~cd}$ & $1.91 \mathrm{c}$ \\
M & $74.45 \mathrm{bcd}$ & $4.28 \mathrm{ab}$ \\
H & $73.63 \mathrm{~cd}$ & $4.68 \mathrm{ab}$ \\
SH & & \\
Fully ripe & $77.93 \mathrm{a}$ & $4.65 \mathrm{~b}$ \\
M & $76.08 \mathrm{abc}$ & $4.61 \mathrm{~b}$ \\
H & $77.41 \mathrm{ab}$ & $5.35 \mathrm{a}$ \\
SH &
\end{tabular}

${ }^{2}$ Three application levels of complete liquid fertilizer containing $60(\mathrm{M}), 120(\mathrm{H})$, and 240 (SH) ppm of N were supplied once a week. Fruits were harvested at the firm-mature stage and stored for $3 \mathrm{~d}$.

${ }^{\text {y}}$ Significant difference by Duncan's multiple range test $(P \leq 0.05)$ for values within each column.
Table 3. Effect of fertilizer application level on the contents of flesh cell wall substances $\left(\mathrm{mg} \cdot \mathrm{g}^{-1} \mathrm{FW}\right)$ in Hakuho peach flesh.

\begin{tabular}{|c|c|c|c|c|c|}
\hline \multirow[b]{2}{*}{ Treatment $^{z}$} & \multicolumn{3}{|c|}{ Pectin $^{y}$} & \multirow[b]{2}{*}{ Hemicellulose $^{x}$} & \multirow[b]{2}{*}{ Cellulose } \\
\hline & WSP & CSP & ASP & & \\
\hline \multicolumn{6}{|l|}{ Hard-mature } \\
\hline M & $2.62 \mathrm{c}^{\mathrm{w}}$ & $1.73 \mathrm{~b}$ & 1.82 & 0.66 & 3.16 \\
\hline $\mathrm{H}$ & $3.38 \mathrm{~b}$ & $1.74 \mathrm{~b}$ & 1.51 & 0.72 & 3.41 \\
\hline SH & $3.75 \mathrm{a}$ & $2.20 \mathrm{a}$ & 1.33 & 0.62 & 2.86 \\
\hline \multicolumn{6}{|l|}{ Firm-mature } \\
\hline M & $2.92 \mathrm{c}$ & $1.99 \mathrm{a}$ & 1.60 & 0.60 & 2.59 \\
\hline $\mathrm{H}$ & $3.15 \mathrm{bc}$ & $1.58 \mathrm{~b}$ & 1.10 & 0.56 & 1.86 \\
\hline SH & $3.55 \mathrm{ab}$ & $1.96 \mathrm{a}$ & 1.60 & 0.67 & 3.18 \\
\hline \multicolumn{6}{|l|}{ Fully ripe } \\
\hline M & $3.09 \mathrm{c}$ & $1.62 \mathrm{~b}$ & 1.23 & 0.50 & 2.47 \\
\hline $\mathrm{H}$ & $3.35 \mathrm{~b}$ & $1.67 \mathrm{~b}$ & 1.04 & 0.45 & 2.24 \\
\hline SH & $3.33 \mathrm{~b}$ & $1.53 \mathrm{~b}$ & 0.77 & 0.50 & 2.50 \\
\hline
\end{tabular}

${ }^{2}$ Three application levels of complete liquid fertilizer containing $60(\mathrm{M}), 120(\mathrm{H})$, and $240(\mathrm{SH}) \mathrm{ppm}$ of N were supplied once a week. Fruits were harvested at the firm-mature stage and stored for $3 \mathrm{~d}$.

${ }^{y}$ Pectic substances were sequentially extracted from alcohol-insoluble solids (AIS) with water, watersoluble polyuronides (WPS), chelator-soluble polyuronides (CSP), and alkali-soluble polyuronides (ASP). The contents are shown as galacturonic acid equivalent $(\mathrm{n}=3)$.

${ }^{x}$ Shown as glucose equivalent $(n=3)$. The extract hemicellulose is a mix of $1 \mathrm{M} \mathrm{KOH}$ and $4 \mathrm{M} \mathrm{KOH}$.

${ }^{w}$ Significant difference by Duncan's multiple range test $(P \leq 0.05)$ for values within each column. content of acidic pectic polysaccharides was increased the $\mathrm{SH}$ treatment as shown by the large peak (subfraction i) eluted at 10 to 22 min. At the firm-mature stage, the content of acidic pectic polysaccharides in the $\mathrm{H}$ treatment fruits was also increased significantly to the level observed in the $\mathrm{SH}$ treatment fruits. However, the increase was only slight in the $\mathrm{M}$ treatment fruits. At the fully ripe stage, the content of acidic pectic polysaccharides was higher in the fruits grown under high fertilizer application levels. In addition to that, a considerable amount of polyuronides eluted with high ionic strength at the elution time of 40 to 50 min was detected in the $\mathrm{SH}$ treatment fruits.

The three subfractions, indicated in Figure 3, were pooled to analyze the molecular mass distribution of the acidic pectic poly- saccharides (Fig. 4). Subfraction i corresponded to the major peaks of the polyuronide from the $\mathrm{H}$ and $\mathrm{SH}$ treatment fruits at the firm-mature stage, comprised low-molecular-mass pectins of $\approx 50 \mathrm{kDa}$. Subfraction ii comprised intermediate-molecular-mass pectins of $\approx 100 \mathrm{kDa}$. Subfraction iii comprised relatively high-molecular-mass pectins of $\approx 100$ to $200 \mathrm{kDa}$.

Juice gellation tests after addition with $\mathrm{Ca}$. The viscosity of juice to which a known volume of $\mathrm{H}_{2} \mathrm{O}$ was added was $\approx 1.5$; no significant difference in juice viscosity was observed among fruits of different maturities and fertilizer application levels (Table 4). Juice viscosity was increased slightly when $\mathrm{CaCl}_{2}$ was added. On the other hand, all the juice became a gel after Tris buffer $(\mathrm{pH} 7.8)$ plus $\mathrm{CaCl}_{2}$ was added, except the juice from
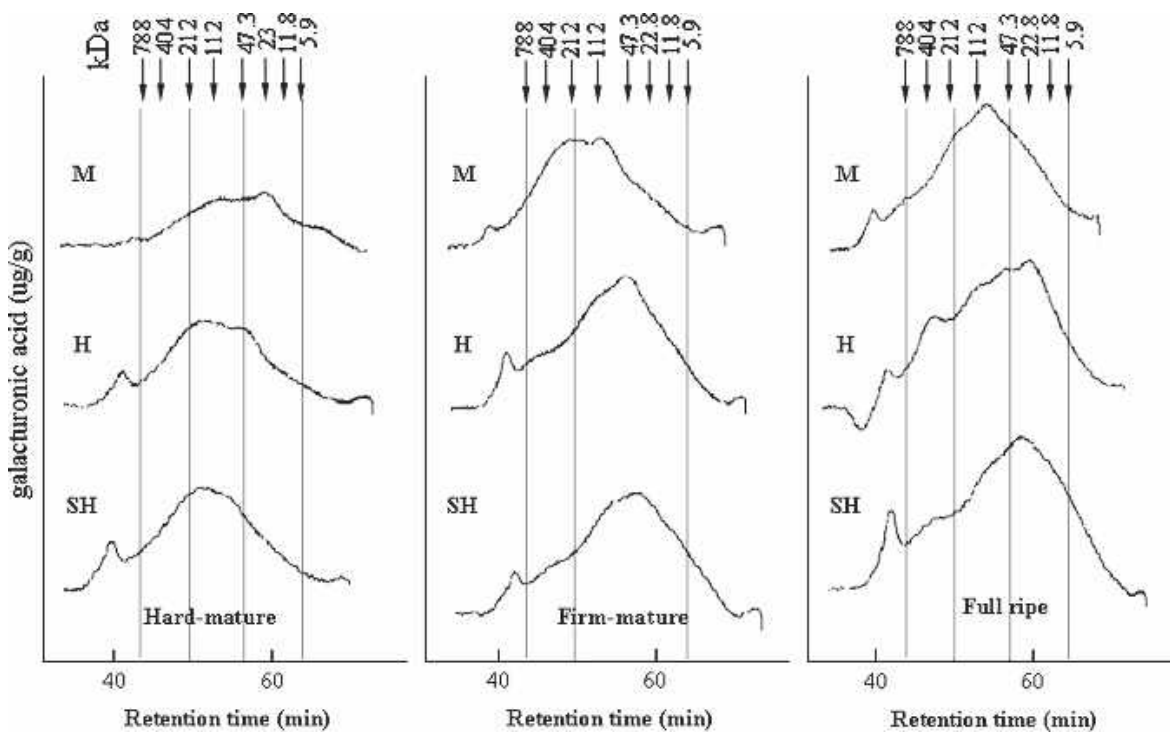

Fig. 2. Molecular mass distribution of gel filtration profiles of water-soluble polysaccharides of alcoholinsoluble solids from Hakuho peach flesh. Details of samples are described in the text. TSK-GEL column $(\mathrm{G} 5000 \mathrm{PW}+\mathrm{G} 3000 \mathrm{PW}, 7.5 \mathrm{~mm} \mathrm{ID} \times 60 \mathrm{~cm} \times 2$, TOSOH) was used for separation. Dextran molecular mass markers $(\mathrm{kD})$ used as a calibration scale are shown at the top. 

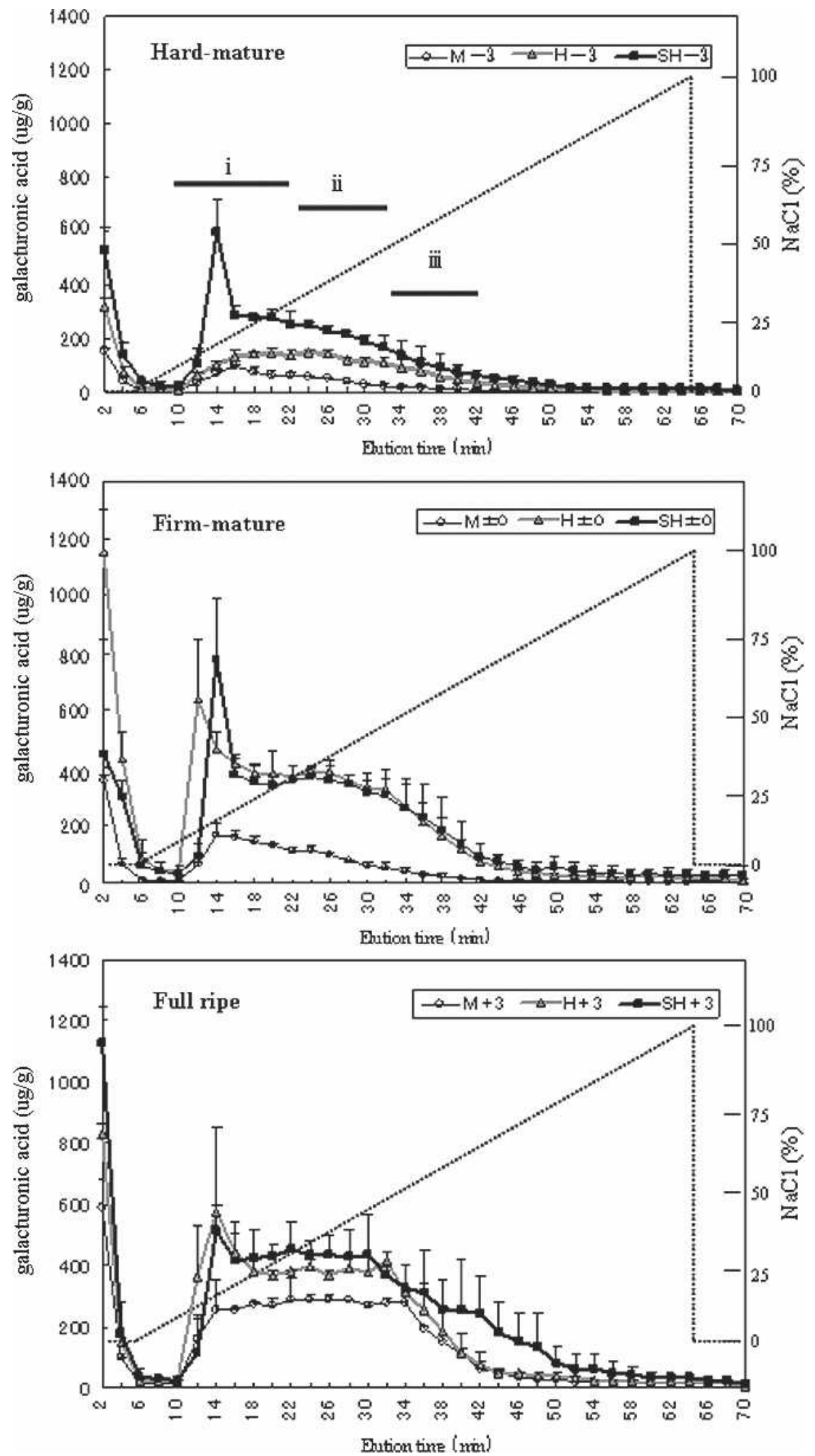

Fig. 3. Elution profiles of polyuronides extracted from alcohol-insoluble solids of Hakuho peach fresh by chromatography on an ion exchange column (quaternary amine column). Details of fruit samples are described in Table 1. Test sample was first eluted with $50 \mathrm{mM}$ Tris- $\mathrm{HCl}$ buffer (pH 8.5) with a linear gradient of $0.5 \mathrm{M} \mathrm{NaCl}$ solution. Fractions of $1.5 \mathrm{~mL}$ were each collected and analyzed for galacturonic acid content.

the $\mathrm{M}$ treatment fruits at the hard-mature and firm-mature stages. At the fully ripe stage, however, a high level of gellation was re- sulted in juice from the M treatment, nearly the same degree to that in the SH treatment at the firm-mature stage.

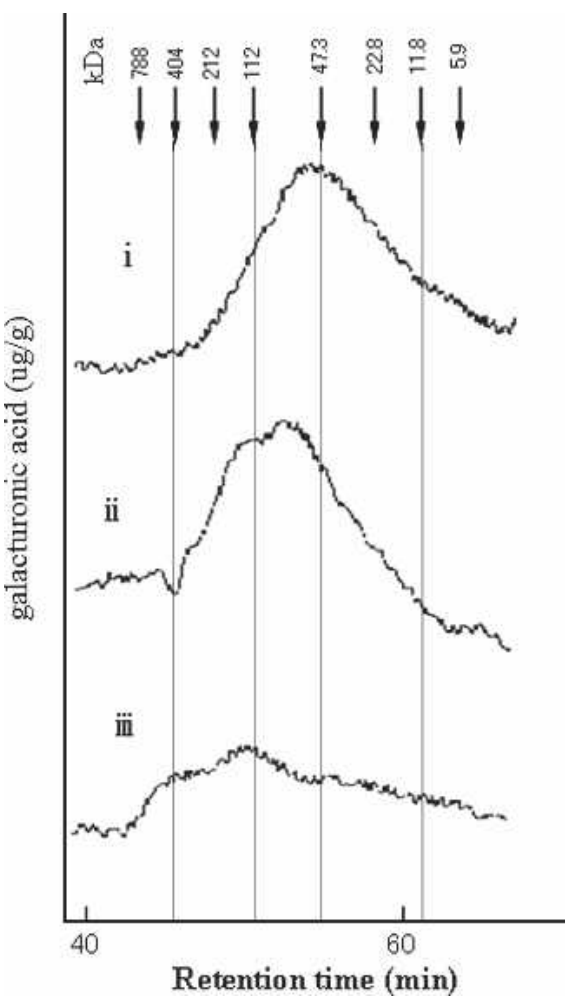

Fig. 4. Molecular mass distribution of gel filtration profiles of three acidic pectic polysaccharide fractions, i, ii, and iii in Figure 3. TSK-GEL G5000PW+G3000PW $(7.5 \mathrm{~mm} \mathrm{ID} \times 60 \mathrm{~cm} \times 2$, $\mathrm{TOSOH}$ ) column was used for separation. Dextran molecular mass markers $(\mathrm{kD})$ as calibration scale are shown at the top.

Table 4. Effect of fertilizer application levels on gel formation Hakuho juice after adding $\mathrm{H}_{2} \mathrm{O}$, $\mathrm{CaCl}_{2}$, and $\mathrm{CaCl}_{2}+$ Tris buffer' .

\begin{tabular}{lllc}
\hline Treatment & \multicolumn{1}{c}{$\mathrm{H}_{2} \mathrm{O}$} & $\mathrm{CaCl}_{2}$ & Tris $+\mathrm{CaCl}_{2}$ \\
\hline Hard-mature & & & \\
$\mathrm{M}$ & $1.26 \mathrm{~b}^{\mathrm{x}}$ & $1.39 \mathrm{c}$ & $1.27 \mathrm{e}$ \\
$\mathrm{H}$ & $1.71 \mathrm{a}$ & $2.01 \mathrm{a}$ & $1.67 \mathrm{e}$ \\
$\mathrm{SH}$ & $1.63 \mathrm{a}$ & $2.10 \mathrm{a}$ & $5.28 \mathrm{c}$ \\
Firm-mature & & & \\
$\mathrm{M}$ & $1.41 \mathrm{ab}$ & $1.50 \mathrm{bc}$ & $1.98 \mathrm{e}$ \\
$\mathrm{H}$ & $1.26 \mathrm{~b}$ & $1.60 \mathrm{c}$ & $4.58 \mathrm{~d}$ \\
$\mathrm{SH}$ & $1.55 \mathrm{ab}$ & $1.80 \mathrm{~b}$ & $8.47 \mathrm{a}$ \\
Full ripe & & & \\
$\mathrm{M}$ & $1.47 \mathrm{ab}$ & $1.90 \mathrm{a}$ & $8.28 \mathrm{a}$ \\
$\mathrm{H}$ & $1.34 \mathrm{~b}$ & $1.67 \mathrm{bc}$ & $6.07 \mathrm{~b}$ \\
$\mathrm{SH}$ & $1.32 \mathrm{~b}$ & $1.77 \mathrm{~b}$ & $5.58 \mathrm{c}$ \\
\hline${ }^{\mathrm{p} H}=7.8$. & & &
\end{tabular}

y Three application levels of complete liquid fertilizer containing $60(\mathrm{M}), 120(\mathrm{H})$, and 240 (SH) ppm of N were supplied once a week. Fruits were harvested at the firm-mature stage and stored for $3 \mathrm{~d}$.

'Significant difference by Duncan's multiple range test $(P \leq 0.05)$ for values within each column.

\section{Discussion}

Pectic substances are noncellulosic constituents of the plant cell wall and play an important role not only in flesh softening, but also in changing the texture of fruit tissue. Our data indicate that peaches from overfertilized trees, like in the cases of $\mathrm{H}$ and $\mathrm{SH}-$ treated fruits, lose flesh firmness at the early stage of maturation, namely the hard- and 
firm-mature stages; this is accompanied by high AIS and WSP contents and low ASP content in the flesh. Such characteristics of fleshy tissue seem to be responsible for the poor flesh texture (Table 1). On the other hand, the CSP content does not seem to affect the texture. Similar results have been reported by Chen and Borgic (1985) and Murayama et al. $(1998,2002)$ for pear. It is possible to assume that a part of ASP is converted into WSP during the ripening process, and this is associated with the softening of peaches. In general, most WSPs are partitioned in fruit juice and they affect the flesh texture of peach, particularly in terms of juiciness and firmness of the flesh; thus, we focused on the investigation of peach juice WSP.

The changes in the molecular mass of WSP indicate that high-molecular-mass substances exist in the $\mathrm{H}$ and $\mathrm{SH}$ treatment fruits than the $\mathrm{M}$ treatment fruits at the hard-mature stage (Fig. 2). Interestingly, marked decreases in WSP molecular size were observed in the $\mathrm{H}$ and $\mathrm{SH}$ treatment fruits at the firmmature and fully ripe stages. On the other hand, at the fully ripe stage, the peak WSP molecular size of the $M$ treatment fruits was constant and significantly larger than those of the $\mathrm{H}$ and $\mathrm{SH}$ treatment fruits. The flesh texture at the fully ripe stage differed notably; it was buttery and juicy in the M treatment fruits and coarse and poorly resilient in $\mathrm{H}$ and $\mathrm{SH}$ treatment fruits.

The analysis of pectic substances in AIS suggested that a large amount of acidic pectic polysaccharides was eluted from 14 to $40 \mathrm{~min}$ only in the SH treatment fruits at the hardmature stage and the $\mathrm{H}$ treatment fruits at the firm-mature stage (Fig. 3). In the case of juice from the $M$ treatment fruits, the amount of acidic pectic polysaccharides was considerably smaller even at the fully ripe stage. These pectic substances, indicated as subfractions $\mathbf{i}$ and $\mathbf{i i}$ in the upper graph of Figure 3 , appeared as peaks ranging from $\approx 50$ to 100 $\mathrm{kDa}$ (Fig. 4) and were considered to be lowmolecular-mass pectins. Particularly in the case of $\mathrm{SH}$ treatment fruits, special acidic pectic polysaccharides that were eluted between 40 and $50 \mathrm{~min}$ were obtained at the fully ripe stage (Fig. 3). That the molecular weight was larger than $110 \mathrm{kDa}$ suggested that in the SH treatment fruits, WSP was degraded in an unconventional manner, resulting in polyuronides with a wide range of molecular masses. These results suggest that the high fertilizer application level impaired the early solubilization of polyuronides re- sulting in the accumulation of low-molecular WSP, which ultimately causes the inferior texture of peaches.

The results in Table 4 indicate that at the hard- and firm-mature stages, the juice from the $\mathrm{SH}$ treatment fruits exhibited a high degree of gellation at high $\mathrm{pH}$ (7.8) and high $\mathrm{Ca}^{++}$conditions, although the juice from the $\mathrm{M}$ treatment fruits did not show such gellation. At the fully ripe stage, however, the juice from the $M$ treatment fruits showed the highest degree of gellation, whereas that from the SH treatment fruits showed the lowest. The juice gellation may be a result of crosslinking between $\mathrm{Ca}^{++}$and small polygalacturonide fragments produced by the degradation of flesh WSP. The early gellation of juice from high-fertilized peach may be an indication of an earlier collapse of flesh pectin in those fruit than in the normally fertilized counterpart. At all stages of maturity, the intrinsic viscosity of the juice from the $\mathrm{M}$ treatment fruits was higher than those of juices from the $\mathrm{H}$ and $\mathrm{SH}$ treatment fruits according to the panel evaluation (data not shown). This indicates that the length of the polygalacturonide chain is related, at least in part, to juice viscosity. Factors other than the length of the polygalacturonide chain and the amount of water-soluble pectin may also influence juice viscosity. Peach softening during ripening has been attributed to the enzymatic degradation of pectic polymers (Callahan et al., 1992; Dowans and Brady, 1990; Pressey and Avants, 1978). Although pectin esterase is considered to be the most dominant pectic enzyme associated with peach softening, other pectic enzymes may well be involved. Further investigation is needed in this area.

\section{Literature Cited}

Blanpied, G.D., W.J. Bramlage, D.H. Dewey, R.L. LaBelle, L.M. Massey, G.E. Mattus, W.C. Stiles, and A.E. Watada. 1978. A standardized method for collecting apple pressure test data. New York's Food and Life Sciences Bulletin \#74. Blumenkrantz, N. and G. Asboe-Hansen. 1973. New method for quantitative determination of uronic acids. Anal. Biochem. 54:484-489.

Callahan, A.M., P.S. Morgens, P. Wright, and K.E. Nichols. 1992. Comparision of Pch313 (pTOM13homolog) RNA accumulation during fruit softening and wounding of two phenotypically different peach cultivars. Plant Physiol. 100:482-488.

Chen, P.M. and D.M. Borgic. 1985. Changes in water soluble polyuronides in the pulp tissue of ripening 'Bosc' pears following cold storage in air or in $1 \%$ oxygen. J. Amer. Soc. Hort. Sci. 110:667-671.

Chen, P.M. and W.M. Mellenthin. 1981. Effects of harvest date on ripening capacity and postharvest life of 'd'Anjou' pears. J. Amer. Soc. Hort. Sci. 106:38-42.

Dowans, C.G. and C.J. Brady. 1990. Two forms of exopolygalacturonase increase as peach fruits ripen. Plant Cell Environ. 13:523-530.

Fishman, M., L.B. Levaj, D.T. Gillespie, and R. Scorza. 1993. Changes in the physio-chemical properties of peach fruit pectin during on-tree ripening and storage. J. Amer. Soc. Hort. Sci. 118:343-349.

Harker, F.R., R.J. Redgwell, I.C. Hallett, S.H. Murray, and G. Carter. 1997. Texture of fresh fruit. Horticultural Reviews. 20:121-224.

Hegde, S. and N.O. Maness. 1996. Sugar composition of pectin and hemicellulose extracts of peach fruit during softening over two harvest seasons. J. Amer. Soc. Hort. Sci. 121:11621167.

Hegde, S. and N.O. Maness. 1998. Changes in apparent molecular mass of pectin and hemicellulose extracts during peach softening. J. Amer. Soc. Hort. Sci. 123:445-456.

Jia, H., K. Hirano, and G. Okamoto. 1999. Effects of fertilizer levels on tree growth and fruit quality of 'Hakuho' peaches (Prunus persica). J. Jpn. Soc. Hort. Sci. 68:487-493.

Jia, H., G. Okamoto, and K. Hirano. 2000. Effect of amino acid composition on the taste of 'Hakuho' peaches (Prunus persica Batsch) grown under different fertilizer levels. J. Jpn. Soc. Hort. Sci. 69:135-140.

Maness, N.O., D. Chrz, S. Hegde, and J.C. Goffreda. 1993. Cell wall changes in ripening peach fruit from cultivars differing in softening rate. Acta Hort. 343:200-203.

Murayama, H., T. Katsumata, O. Horiuchi, and T. Fukushima. 2002. Relationship between fruit softening and cell wall polysaccharides in pears after different storage periods. Postharvest Biol. Technol. 26:15-21.

Murayama, H., T. Takuhashi, R. Honda, and T. Fukushima. 1998. Cell wall changes in pear fruit softening on an off the tree. Postharvest Biol. Technol. 14:143-149.

Okamoto, G., H. Jia, A. Kitamura, and K. Hirano. 2001. Effect of different fertilizer application levels on texture of 'Hakuho' peaches (Prunus persica Batsch). J. Jpn. Soc. Hort. Sci. 70:533538.

Pressey, R. and J.K. Avants. 1978. Differences in the polygalacturonase composition of clingstone and freestone peaches. J. Food Sci. 43:1415-1423.

Reeve, R.M. 1970. Relationships of histological structure to texture of fresh and processed fruits and vegetables. J. Texture Stud. 1:247-284.

Sams, E. 1999. Preharvest factors affecting postharvest texture. Postharvest Biol. Technol. 15:249-254. 